\title{
The impact of information culture on information/records management
}

A case study of a municipality in Belgium

\author{
Proscovia Svärd
}

Faculty of Humanities, University of Amsterdam, Amsterdam, The Netherlands

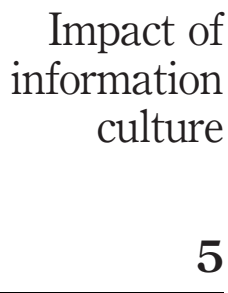

Received 9 April 2013 Revised 5 November 2013 Accepted 5 November 2013

\begin{abstract}
Purpose - The purpose of this article is to examine the information culture of a medium-sized municipality in Belgium. Public information/records is/are one of the most important instruments of citizens' control of public authorities. The principle of Public Access gives citizens a right to access public records, while the Privacy Act protects the integrity of the citizens. Municipalities are institutions that intensely interact with the citizens. Therefore, the way they handle the information that is generated during this interaction is of crucial importance to the efficient service delivery, safeguarding the rights of the citizens that they serve and for sustaining the open governance structure that promotes the principles of accountability and transparency.

Design/methodology/approach - The author employed a case study approach in order to establish the attitudes and norms the organizational employees had towards the management of information/records. She also applied the information culture assessment framework developed by Oliver during the design of the research questions.

Findings - Information culture affects the way public information/records are managed. Though investments are being made in information systems to facilitate the capture and management of information/records, the people issues are equally as crucial. E-Government development will require an information culture that promotes effective creation, use and management of information, if its goal of efficient and transparent public administrations is to be achieved.

Originality/value - The originality of this study lies in the application of the information culture assessment framework that was developed by Oliver. The framework facilitates the formulation of questions using its three layers to tease out the information required by a researcher in an attempt to draw conclusions regarding the attitudes, norms and the value the interviewees attach to information/records.
\end{abstract}

Keywords Organizational culture, Culture, e-Government, Information culture, Information/records management, Record

Paper type Case study

\section{Introduction}

This paper examines the information culture in a medium-sized municipality in Belgium. The way information is managed has consequences for service delivery. Information is viewed as the currency or fuel that drives today's organizations (Feldman and Villars, 2006). It is dynamic, creates great value and is seen as the "glue" that holds organizations together (Bantin, 2008). Information plays a major role for

The author would like to acknowledge the support of the Archivist of the Municipality where the author carried out this research and all the participants who were willing to share their knowledge.

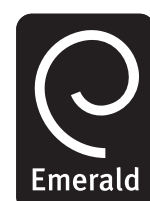

Records Management Journal Vol. 24 No. 1, 2014 (c) Emerald Group Publishing Limited 0956-5698 DOI 10.1108/RMJ-04-2013-0007 
RMJ

24,1

6

both business purposes and democratic developments. In democratic countries it enhances the accountability of public authorities. Municipalities are institutions that intensely interact with the citizens. This interaction generates a lot of public information. Therefore, the way the municipalities handle the information generated during this interaction, is of crucial importance to the efficient delivery of services, safe guarding the rights of the citizens that they serve, and for sustaining their open governance structure. Municipalities are therefore required to create, organize, manage, use and preserve their records according to the laws governing public information. In Belgium, access to municipal records is guaranteed by constitution. Article 32 of the Constitution was amended in 1993 to include a right of access to records held by the government:

Everyone has the right to consult any administrative document and to have a copy made, except in the cases and conditions stipulated by the laws, decrees, or rulings referred to in Article 134[1].

There are also Public Access and Privacy Acts which promote access to public information/records and also, protect the integrity of the individuals.

The increased demand by citizens for efficient service delivery from public sector organizations has implications for the information that underpins those services (Torres et al., 2005). Robust and effective information management is required. To address the need for more services and for more efficient service delivery, most governments are promoting e-Government initiatives which have the use of information technology at their core. The increase in the channels through which citizens interact with the municipalities requires information and records management strategies that will capture the information generated as well as the records that are created through these various interactions. Information management systems have been deployed to help with the capture, management, organization and use of the records. "People issues" are often left out of the equation, but are proving to be a substantial obstacle to the successful implementation of these systems (McLeod et al., 2011). There is an assumption in some organizations that since we are all document creators, we are equally good records managers. This assumption is not promoting effective information management. It is argued by information culture researchers that the attitudes, norms and the value employees of an organization put on information all have an impact on business efficiency. This is what is referred to as "information culture" (Ginman, 1993; Choo et al., 2008; Oliver, 2008; Douglas, 2010). An organization is said to have a mature information culture when information access and use is integrated into its daily activities (Curry and Moore, 2003; Douglas, 2010). Information culture is also said to be intertwined with organizational culture (Oliver, 2011; Douglas, 2010; Choo et al., 2008). Alvesson was of the view that there is enormous variation in the definition of the term organizational culture, and he used it as an umbrella concept for a way of thinking which takes a serious interest in cultural and symbolic phenomena (Alvesson, 2002). Organizational culture could therefore mean the importance that people attach to symbolism the interpretation of events, ideas and experiences that are influenced and shaped by the groups within which they live. Information culture is formed and practiced in the organizations and therefore influences the approaches organizations employ to manage their information/records.

Davenport (1997) has argued that organizations should pay less attention to information systems but focus more on the "people issues". Based on my own work 
experience I have seen a trend where some organizations disregard the soft people issues and instead invest in information systems as a quick fix to their information management challenges. This kind of approach often leads to the implementation of expensive information management systems that fail to deliver the expected results. The purpose of this article is to examine the information culture of a medium-sized municipality in Belgium and to establish the impact it this had on the management of information/records. I begin by outlining the objectives of the research, followed by the method employed to the research, presentation of relevant literature and a discussion and conclusion.

\section{The research questions}

The objective of this research was to study the impact of information culture on the management of information/records in a medium-sized municipality in Belgium. The research therefore addressed the following two questions:

Q1. What type of information culture exists in the municipality?

Q2. How does information culture impact on the capture, management, organization and pluralization of public records in this municipality?

\section{Literature review}

A review of relevant literature found that most articles discussed organizational culture in relation to information systems implementation (Enrique et al., 2001; McGrath, 2003; Indeje and Zheng, 2010). Very few articles addressed information culture as a concept or in relation to information/records management.

\subsection{Culture as a concept}

Culture is defined by Buch and Wetzel (2001, p. 40) as "a pattern of shared basic assumptions that the group learned as it solved its problems of external adaptation and internal integration, that has worked well enough to be considered valid and, therefore, to be taught to new members as the correct way to perceive, think, and feel in relation to those problems". Alvesson (2002) posits that a cultural perspective facilitates a better understanding of organizations and defined culture as the setting in which behaviour, social events, institutions and process take place and are understood. The cultural dimension is therefore central to aspects of organizational life. Alvesson argues that the centrality of culture as a concept comes from shared meanings and that organizations are systems of shared meanings. Ideas or beliefs held in common reduce misunderstandings or erroneous interpretations of meanings. Hofstede (2001, p. 9) provides an anthropologically agreed on definition of culture as, "patterned ways of thinking, feeling and reacting, acquired and transmitted mainly by symbols, constituting the distinctive achievements of human groups, including their embodiments in artefacts; the essential core of culture consists of traditional (i.e. historically derived and selected) ideas and especially their attached values." Culture does not take place in a vacuum but is embedded within organizational culture.

\subsection{Organizational culture}

Ezadi Yeganeh (2007), argues that organizational culture consists of behavioural and cognitive characteristics and can be divided in three layers:

\section{Impact of information culture}


RMJ

24,1

8

(1) The outer layer: strategies, missions and objectives of the organization.

(2) The middle layer: beliefs about the issues that organizational employees talk about.

(3) The inner layer: aspects of organizational life that people find difficult to recall and explain.

Organizational culture is therefore the basic underlying assumptions and these are taken-for-granted beliefs, perceptions, thoughts and feelings. Buch and Wetzel (2001) argue that this is where the difficulty lies in changing an organization's culture. Organizational culture is intrinsically linked to information culture because the effective use of information in an organization is determined by human actions

\subsection{Information culture}

In 1998 Höglund conducted a case study of information behaviour in a pharmaceutical company. He argued that even though literature on organizational culture was growing, there was little use of the concept "information culture." He defined information as part of corporate culture and concluded that a corporate culture that emphasised information issues was related to positive company performance. The connection between information culture and positive performance had been made earlier in empirical study carried out in collaboration with the British Library Research and Development Department in 1995. This study set out to determine whether there was a correlation between information culture and business success (Grimshaw, 1995). This study confirmed that human information activities gave organizations a competitive edge. The quality and value of information, its sources, management and communication were critical to the success of an organization.

Davenport like Grimshaw emphasizes a human-centred approach to information management. He argues that a lot of focus had been put on Information Technology and yet, better computers and communication networks did not necessarily lead to better information environments. He proposes instead the term "information ecology" which puts a narrow focus on technology but addresses the way people create, distribute, understand, and use information. He argues that putting in place an information ecology required new management frameworks, incentives and attitudes towards organization hierarchy, complexity and division of resources (Davenport, 1997). Davenport, defines ecology as and as "holistic management of information" or "human-centred information management" (Davenport, 1997, p. 11). He postulated that this kind of thinking put humans at the centre of the information world and technology on the periphery. He believed that ecological approaches to information management were more modest, behavioural and practical compared to the grand designs of information architecture and machine engineering.

Widén-Wulff (2000) conducted a qualitative study that reviewed information cultures in 15 Finnish insurance companies. She also pursues an argument similar to Höglund that information culture is intertwined with organizational culture. She highlights the correlation between a rich information culture and successful business performance, as also demonstrated in Grimshaw's study. Widén-Wulff is concerned with the internal information flow and how a rich information culture and functioning knowledge creation were connected to successful performance. She contends that information culture is about information systems, common knowledge, and individual information systems in form of attitudes and information ethics. She concludes that the 
organizations she reviewed were aware of the importance of information, but argues that it was the most difficult asset to manage (Widén-Wulff, 2000).

Curry and Moore (2003) further confirm the connection between information culture and organizational culture. They use organizational culture as a starting point for their research on information management in healthcare. Finding it difficult to quantify and qualify culture and information, they discuss the need for a tool to measure and develop an information culture They argue that despite the frequent use of information culture a concept in the literature there is no agreed on definition and posit that it requires a well developed organizational culture in order for it to be nourished. This further clarifies why information culture and organizational culture are intertwined. The two concepts have common attributes in the form of values, assumptions and beliefs. Six years after Davenport's argument against the focus on information technology as a solution to information management issues, they also concluded that the adoption of information technology alone is not sufficient. To deliver effective information management information technology has to be complemented with a good information culture (Curry and Moore, 2003).

Oliver (2004) carried out comparative case studies and investigated information management in three universities in Australia, Hong Kong and Germany. She aimed to enhance an understanding of the interactions of organizational culture with information and its management. Her research perspective was grounded in the fact that the values and attitudes accorded to information demonstrate information culture. She suggests that there is a need to understand external as well as internal factors in order to diagnose information culture, since organizations are part of a broader societal context.

Information culture is defined by Choo et al. (2006) as the organization's values, norms and practices towards the management and use of information. They carried out a case study of a large Canadian law firm where finding, sharing and processing information was critical to the organization's operations. They argue that information values and information culture play an indispensable role in defining how people share and use information. They consider information behaviours from a perspective of information management, information culture and information use. They distinguish between values and norms as follows:

- Values relate to the organization's perception of the role and contribution of information to organizational effectiveness. Values underlie the organizational style of managing the creation and use of information.

- Norms are derived from values and are socially accepted rules or standards that define what is normal or to be expected within the organization. They can be informal or formal. Informal norms and attitudes influence the creation, flow and use of information by individuals or groups. Formal rules, routines and policies are intended to plan, guide and control information as an asset (Choo et al., 2006).

They claim that in order for organizations to achieve superior business performance, they should have the following capabilities:

- Information technology practices: the capability to manage IT applications effectively and infrastructure to support operations, business processes, innovation and managerial decision making.

- Information management practices: the capacity to manage information effectively over the life cycle of information use, including sensing, collecting, organizing, processing and maintaining information.

\section{Impact of information culture}


RMJ

24,1

10

- Information behaviours and values: the capability to instil behaviours and values in people which promote the effective use of information.

Choo et al. (2008) explore the link between information culture and use in three organizations. Their aim was to establish whether there was a systematic way to identify the information behaviours and values that characterize an organization's information culture. Their research settings included a public health agency, a national law firm and an engineering company. Among the influences they found which shape the information culture of an organization are mission, history, leadership, employee traits, industry and national culture. Again they assert that information culture as a concept has not been adequately explored in current research. The results of their 2006 research demonstrate that different organizational issues need to be effectively managed if information is to be leveraged in a manner that gives a competitive advantage.

Douglas (2010) carried out a qualitative study to explore the values, attitudes, beliefs and behaviours that government departments in Western Australia show towards information. Even though information is pervasive in all government departments, she contends that the value the departments ascribe to it, their attitudes and behaviour towards it are not well understood. Her study found information culture to be complex, systemic and reflexive. She also identified intricate relationships between information culture and organizational culture, information management and information use. Like Curry and Moore (2003) she asserts that although information culture is frequently used as a concept, there is no agreed on definition. She highlighted a paucity of research into information culture which gives organizations a competitive advantage if well aligned with business strategies (Ginman, 1993; Douglas, 2010).

Davenport (1997) postulates that all organizations have models of information governance which are said to be political systems. These models form local or centralized control of information management. The governance attitudes determine how supportive and effective the information culture is. In order to be able to establish the dominant information/records management model in an organization, Davenport's research outlined the following models:

- Information federalism: based on consensus and negotiation regarding an organization's key information elements and reporting structures.

- Information feudalism: individual business units manage their own information, define their own needs and report only limited information to the overall organization.

- Information monarchy: information categories and reporting structures are defined by firm's leaders who may or may not share information after collecting it.

- Information anarchy: absence of any overall information management policy, individuals obtain and manage their own information.

Davenport was of the view that all organizations have some sort of information governance model regardless of size.

This literature review has ascertained that information culture plays an important role in enabling organizations to achieve a competitive edge through the effective use of information. It has further suggested that information culture and organizational culture are intertwined. Information culture as a concept has not been fully explored and therefore this study contributes to the existing research. 


\section{The method}

In case studies, specific cases are examined and Creswell (2007) argues that a case study approach is appropriate when an inquirer seeks an in-depth understanding of the phenomena studied. The goal of the analysis in the case study method is to reflect on the complexity of human interaction from the perspective of the respondents based on actual events, and to make this complexity intelligible to others (Rubin and Rubin, 2005). Through data analysis, an understanding of the complexity of the case emerges. Case studies offer a variety of evidence through interviews, documents, artefacts and observations (Yin, 2009). It is through data collection that a researcher is able to give a detailed description of the case being studied.

Patton (2002) argues that researchers interview people because we cannot observe everything. Feelings, thoughts and intentions are hard to observe. Observing how people have organized the world and the meanings they attach to what goes on in the world is difficult. Interviews therefore allow us entry into other people's worlds. I used a municipality located in Belgium as my case study and examined its information culture and the impact it had on the management of information/records. I also conducted interviews in November, 2012 and February, 2013. These interviews facilitated my understanding of the type of information culture that exists in the organization. My interaction with the interviewees enabled me to observe and access their attitudes and norms and to understand how they valued the public records they generated or received. A total of 21 interviews were conducted, transcribed and analysed. The categories of people interviewed included heads of departments, heads of units, architects, environmental officers, GIS managers, secretaries, building permits granting officers, an archivist, IT personnel, social workers, two top management members and a legal advisor.

In order to establish the existing culture in the municipality, I used Oliver's (2011) framework for the analysis of information culture in organizations. I formulated an interview guide with questions that related to the three different levels of the framework.

- The first level deals with the fundamental layer of an organization's culture. It includes respect for information as evidence that is the records themselves, respect for information as knowledge; willingness to share information; and trust in information.

- The second level addresses employee skills, knowledge and experience related to information management.

- The third level is about information governance and trust in organization information systems.

The management of information amidst e-Government developments has become a complex issue. This is what motivated me to use the qualitative approach in order to understand how the employees of the municipality valued records and to establish the type of information culture espoused by the municipalities.

\section{The research findings}

The section which follows presents the research findings presented according to Oliver's (2011) information culture assessment model as defined in the previous section.

\section{Impact of information culture}


RMJ

24,1

12

\subsection{Respect for information as evidence}

The municipality's information/records environment constituted a hybrid system of paper and electronic records. Records were received both in a paper format and by e-mail, but it was normally the paper records that were considered as official records. Electronic records were at times recognised as official records and at times not, depending on the nature of the case. It was up to each officer to judge whether an e-mail had more than ephemeral value and whether it qualified to be regarded as an official record. All the interviewees confirmed that the municipality did not have an information/records management policy and this partly explained why there were so many personalised systems in the organization. Most e-mails were retained in the officers' e-mail boxes and personalised structures. E-mail correspondence was deleted without consultation with the archivist and therefore without applying any appraisal procedures. This was particularly because e-mail boxes were by legislation private and hence beyond the access of the function that is supposed to manage information/records on behalf of the organization. The archives service did not have a mandate from management to intervene in the management of active records. A few of the interviewees who had worked for the city long enough knew that there was an e-mail policy but the majority did not know it existed. The e-mail policy required all employees to take care of their e-mails by printing them out on paper and archiving them.

Some interviewees argued that management was aware that the management of records was a problem and that they needed to deal with it but, did not have time to seriously engage and commit themselves to finding a solution. A head of department argued that records management was not highly profiled because:

In the eight years I have worked here the discussion on records management has been once or twice on the agenda. That is too little. It is also a responsibility of the management team with two directors, the secretary of the municipality here; it should be of concern to them also. These interviews should be on the management agenda and again on the agenda of the head of departments.

He also stated that co-ordinating and managing the circulation of large amounts of information around the organization was a problem. He believed that there were a few people in the organization who would like to improve the information management environment but they did not have time. The interviews confirmed that from top management down to lower ranked officers, people were constantly looking for records. This was even worse for newly recruited personnel who spent the first period of their employment trying to figure out where they could find the information/records they needed. In despair, they had instituted their own records management systems.

5.1.1 Respect for information as knowledge, information sharing and trust in information. There was some degree of awareness of the need to maintain records but this was not from a perspective of knowledge management or information sharing but to manage one's own business process. The interviewed officers did not have in mind an enterprise-wide access attitude to their records. The following officer, for example explained that:

Well I know that it is important to keep records of everything and so in this sense I am very organized. I keep records of everything I do and that may be too much but this is for my own purposes but not for the purpose of the municipality or for archiving the records.

Most of the interviewees looked at the archives purely as a repository to maintain records for future generations or for historical records, and not as knowledge bank to 
be readily used. There were however two units that confirmed regular contact with the archives in order to re-use old records. There were no fully developed systems to facilitate knowledge capture and information sharing since people had personalized systems and some of the existing databases were not integrated in a manner that enhanced access. The common system that had been put in place to facilitate the capture of records and hence information sharing was not fully developed and only captured the incoming records but not the outgoing ones. Attempts had also been made to implement a folder structure to facilitate information sharing but it grew out of control. There were no standardized ways of creating and naming folders and the structure therefore created more confusion and made it harder to access vital information. Given that these attempts to facilitate records capture, knowledge management and information sharing had failed, some of the interviewees did not trust that the records contained in the systems were the correct versions. This further promoted the use of personalized systems since individual employees felt they had better control over records in their own electronic folders or paper systems.

\subsection{Employee skills, knowledge and experience related to information management}

All the people interviewed said that they had never been offered training in records and information management. Three of the people interviewed had worked for the municipality for more than 12 years and confirmed that as new members of staff, they had attended an obligatory course on legislation. Since employees lacked corporate guidelines to follow, they had all conceived their own systems. The following head of department argued that as a result of lack of records management training:

The employees start work, they produce records and when they leave very suddenly it is a problem. Everything stays in the computer and the next worker has to search for them. They have their own system sometimes when they start.

Since the employees were not offered training in records management it was surprising to discover that some of the interviewees did not particularly understand the role records and archives management might play for the municipality. Interviewees did not understand why they had to take care of the records. Some confessed that their information/records management skills were not good and requested training courses or instruction sessions on information/records management. While most of the participants admitted that records management was part of their responsibilities they saw it was time consuming. If they were obliged to undertake archiving without knowing how to go about it, then they did not feel motivated and hated doing it. One of the participants confessed that all her fellow employees at the unit hated it.

The following quotations demonstrate a lack of understanding of the role of maintaining records:

I think they exaggerate with the obligation of handling records in the registry. To motivate the people is difficult.

The archives service has to explain better to me why I have to keep these papers. These papers are in my computer. I keep them for a long time. Why do I have to give them to the service of the archives? I have them in my computer. I write a letter to an inhabitant, why I have to keep it for ten years.

It is work that sometimes is a waste of time for me. I have a lot of work and when I give papers to the archives, it is about the selection list, you have to throw these things, no duplicates, it is a waste of time.

\section{Impact of information culture}


RMJ

24,1

14

I make an effort for myself and documents that are important. I keep them in my office because I have my own system. I file everything very well but I keep them for the time I need them but when there is a project and it is finished and two years later, I do not need the documents I clean my office and I sometimes throw them away. Yes.

Lack of guidelines and an information/records management policy made it hard for staff to take care of information/records in a manner that promoted the interests of the municipality. Managing records was not a natural process but something that was seen as quite cumbersome. Though a necessity, the interviewees did not feel motivated to do it since it was time consuming and they lacked the skills and knowledge. In this complex environment, it was the officers who were supposed to know the different laws governing their respective areas of work and hence the administrative value of the records that they generated. They could get help from the archives service as far as establishing the historical value of the records was concerned. Lack of clear guidelines or knowledge about the laws that govern records retention ought to be kept created insecurity in appraising and destroying information/records. The following officers argued that:

I keep everything. I keep most of the things but may be then I throw away things that are important. I try to keep everything on the computer and on paper too.

For the moment I just try to make sure that my files are not disorderly. I keep them very well but I don't know what I have to keep and so I keep everything, one copy of everything.

"I keep everything" was an expression used by most interviewees and this could be clarified as a safeguard against throwing away useful records. This created an information overload in the organization which in turn overshadowed vital information and clogged information systems.

\subsection{Information/records governance and trust in organizational information systems}

The City had made some efforts to implement common information systems to manage records. However some of these systems were not user friendly and lacked information security functionality. Access to the information in this system was not controlled, and one interviewee lamented being able to see types of records to which she was not supposed to have access. These complications forced people to create their own systems. The interviewees expressed fear of not being able to retrieve the records they registered in the common system because of a complicated user interface. The following quotes demonstrate what people felt about this system:

The systems we have they are not user friendly and of good enough quality. I do not make any effort to put my documents in them because nobody uses them.

Because it is not user friendly and it is very difficult to retrieve information. If I make a document in the system, it is very difficult to get it back.

Because nobody [...] nobody uses it is not true but there are a lot of colleagues who do not use it either. They say we have never done it and then you just don't do it too but we have a lot of discussions about it because one of our colleagues uses it all the time.

However, even those who used the common system on a regular basis also confirmed that it was not at all user-friendly and that it was insufficient for the management of records.

The personalized records management systems were therefore sometimes a result of lack of trust in the common systems put in place to manage organizational 
information/records. I also observed that most of those who managed their own systems of records, were convinced that they were doing it to facilitate their work whilst others did it because they did not trust the central archives to maintain the structure of their records. For example, one interviewee was wary that his records might be appraised and thrown away and yet he was the one who understood their value and not the archives service. The following quotes demonstrate both the confidence people had in their own systems and the lack of trust in the common systems:

I think they are quite good (the records) for myself because I always find what I need and I can easily, in some seconds, look up what I need. And if somebody or a colleague asks for information, I can find it very easily.

Now it is ok for me because I can find everything I want. But I do not think it is an ideal situation for the organization because someone else will not find in the digital archives because they do not know my system. So it is not ideal.

The people who had confidence in their own systems were also aware that they personalized organizational knowledge and that this was not good for the organization. Some of the interviewees claimed they had systems that they themselves could comprehend but they also understood that should they fall sick or leave the city, very few others would be able to understand what was going on in their particular area. Some of these personalized systems also became inefficient as the volume of records grew and without search functions, the retrieval of documents became very time consuming. One of the employees confirmed that she has to go through all the electronic or physical folders to find the record she needs to consult. The previous quotes also clearly demonstrate the lack of understanding for records as a common resource/-or knowledge base but also respect for the maintenance of records as sources of evidence of the transactions that transpire between the municipal employees and the citizens.

The majority of the interviewees suggested that information/records management was not well integrated in the business processes. The interviewees gave different reasons that as new recruits, they had not been informed about how to handle information/records. The introductory course for newly recruited officers offered a lot of information but did not include records management issues. The only training offered regarding the management of information/records was in connection with the implementation of a new system or application. The following interviewees argued that information/records management was not prioritized:

It is not prioritized and not integrated but, in the last years, we have made some improvements and that is thanks to the service from the archives, the archivist who has tried to coach the services to archive.

May be it is not prioritized enough. They do now because we have a deadline to put together our archives and now it is really a hot item in our office. Everybody is panicking, oh my God, how I am I going to do it. So now it is important but there are months that we don't really hear anything about it and then you just forget it because you have your other work and you just keep your documents that you think you have to keep.

Some of the officers in leading positions told me that they do not create or handle records but their main function is to manage people. Responding to the question of whether managing records was part of their responsibilities, departmental and unit bosses said:

\section{Impact of information culture}


RMJ

24,1

16

We have no time. I have a more coaching function here, so it is a little bit hard to say who ...

If it is necessary, yes, but for my work, it is most of the time not important.

This could partly explain why it had proved so difficult to implement effective information/records management regimes since records management requires the engagement and support of top management.

\section{Discussion and conclusion}

The objective of the study was to examine the type of information culture that exists in this medium-sized municipality in Belgium and the impact it has on the creation, capture, organization, management and pluralisation of public records. The literature review revealed that little research has been done on the impact of information culture on information/records management. Information culture has been defined as the norms, attitudes and the manner in which the employees value information (Oliver, 2011). Information culture is intertwined with organizational culture and this because the attitudes and norms that constitute information culture are developed within an organization. Based on the literature reviewed, a good information culture can be said to encourage good information management and the development of good information practices. This determines the management of information for accountability and transparency and for the execution of business processes. An organization has a mature information culture when it accesses and uses information in its everyday activities (Curry and Moore, 2003; Douglas, 2010). The interviews revealed that from top management to down, the municipal employees constantly looked for records in order to manage their daily activities. When information could not be readily accessed a lot of valuable time was wasted. Earlier studies confirmed a correlation between information culture and business success. Grimshaw argues that it is the human information activities that give organizations a competitive edge (Grimshaw, 1995) and Widén-Wulff's research also confirms that a rich information culture enhances business success (Widén-Wulff, 2000). If this municipality is to engage in e-Government development, it will need to address the attitudes and norms that are currently being espoused by its employees. The current information management environment does not promote effective service delivery. Davenport (1997) recommended an approach that focuses on the people rather than the technology. According to his models of information governance this municipality falls under the model of information anarchy: an absence of any overall information management policy, where individuals obtain and manage their own information. Choo et al. (2006) emphasised the importance of good information technology practices, information management practices and information behaviour. In this municipality, the information technology systems put in place to manage official information/records were not used by all members of staff. The complicated user-interface made it difficult for the employees to trust the system since they could not retrieve their records without consulting the IT department or the person in charge of the system. Lack of an information management policy created an environment with no standardized ways of managing information/records. People instead engaged in the creation of their own structures/systems to manage their records.

Records are a special type of information that Oliver (2011) refers to as "information as evidence" and play a crucial role in public administrations because, they enhance accountability and transparency. They also enable the organization to make informed 
decisions (McKemmish, 1997). When organizations lack the culture to manage records well, inefficiency and violation of the laws governing public access and privacy are likely to be violated. The registry function was, for example, not fully developed and even though an attempt had been made to capture incoming correspondence, the replies to this correspondence could not be captured since they were distributed to the different officers and nobody knew what happened to them. Privatization of the e-mail box meant that public information was also privatized but also so was organizational knowledge since e-mail boxes contain lots of information. Failure to accept e-mail as an official record is also problematic, in the light of the fact that this municipality plans to work entirely digitally by the end of 2014 .

The list of challenges included:

- lack of an information management policy;

- lack of knowledge of the legislation governing the appraisal of records;

- lack of training in records management;

- lack of trust in common information systems;

- uncoordinated destruction of records and personalized information systems;

- lack of knowledge management and information sharing systems; and

- trust in information/records.

The interview findings demonstrated lack of respect for information/records as a common resource and knowledge. Further, there was lack of training and hence employee skills were not adequate for understanding the implications of their attitudes towards information/records management. It was also clear that there was lack of information governance and trust in the information systems. Personalized systems were the norm. The municipality was lacking on all the three layers of Oliver's framework for assessing information culture and could be said to have an immature information culture since Curry and Moore (2003) and Douglas (2010) referred to organizations who had information access and retrieval integrated in their daily activities as mature.

In conclusion and to answer the questions that the research set out to examine, the findings showed that the municipality had an immature information culture and an anarchistic information governance model (Davenport, 1997). Lack of an overall information management policy made it hard to create, capture, organize and to manage the generated information/records. Due to lack of guidelines regarding the appraisal of records, important records were likely to have been destroyed. This kind of environment did not promote the use of information/records as a common resource or respect for public records. The challenges listed and the attitudes demonstrated in the research findings meant that pluralization of records was likely to be difficult. Involvement in e-Government development is going to prove difficult without robust information/records management regimes and if the organization fails to uproot the existing information culture.

\section{Note}

1. Constitution of Belgium, 1994, available at: www.uni-wuerzburg.de/law/be00000_html

\section{Impact of information culture}


RMJ

24,1

18

\section{References}

Alvesson, M. (2002), Understanding Organizational Culture, Sage Publications, London.

Bantin, P.C. (2008), Understanding Data and Information Systems for Recordkeeping, Facet Publishing, London.

Buch, K. and Wetzel, D.K. (2001), “Analyzing and realigning organizational culture”, Leadership \& Organizational Development Journal, Vol. 22 No. 1, pp. 40-43.

Choo, C.W., Bergeron, P., Detior, B. and Heaton, L. (2008), "Information culture and information use: an exploratory study of three organizations", Journal of the American Society for Information Science and Technology, Vol. 59 No. 5, pp. 792-804.

Choo, W.C., Furness, C., Paquette, S. and Van den Berg, H. (2006), "Working with information: information management and culture in a professional services organization", Journal of Information Science, Vol. 32 No. 6, pp. 491-510.

Creswell, J.W. (2007), Qualitative Research \& Evaluation Methods, 3rd ed., Sage Publications, London.

Curry, A. and Moore, C. (2003), "Assessing information culture - an exploratory model", International Journal of Information Management, Vol. 23 No. 2, pp. 91-110.

Davenport, T.H. (1997), Information Ecology: Mastering the Information and Knowledge Environment, Oxford University Press, Oxford.

Douglas, J. (2010), The identification, development and application of information culture in the Western Australian public sector, doctoral thesis, Faculty of Computing, Health and Science, Edith Cowan University, Joondalup.

Enrique, C., Llopis, J., González, R.M. and Gascó, J.L. (2001), “The performance of Information System through organizational culture", Information Technology \& People, Vol. 14 No. 3, pp. 247-260.

Ezadi Yeganeh, M. (2007), "The impact of national and organizational culture on information technology (IT)”, National Studies on Librarianship and Information Organization, Vol. 8 No. 1, pp. 20-34.

Feldman, S.R. and Villars, L. (2006), "The information lifecycle management imperative", White Paper, available at: ftp://ftp.compaq.com/pub/la/products/idc_lifecycle_management_ imperative.pdf (accessed 17 August 2012).

Ginman, M. (1993), Information Culture and Business Performance, Institution för biblioteksvetenskap och informatik, Ảbo.

Grimshaw, A. (1995), "Information culture and business performance", Information Strategy Report, Vol. 2, p. 74.

Hofstede, G. (2001), Cultures, Consequences: Comparing Values, Behaviors, Institutions and Organizations Across Nations, Sage Publications, Thousand Oaks, CA.

Indeje, W.G. and Zheng, Q. (2010), "Organizational culture and information systems implementation: a structuration theory perspective", available at: http://sprouts.aisnet. org/10-27 (accessed 2 February 2012).

McGrath, K.M. (2003), “Organizational culture and information systems implementation”, $\mathrm{PhD}$ thesis, London School of Economics and Political Science, London, available at: http:// www.lse.ac.uk/collections/informationSystems/pdf/theses/mcgrath2.pdf (accessed 9 March, 2012).

McKemmish, S. (1997), "Yesterday, today and tomorrow: a continuum of responsibility", Proceedings of the Records Management Association of Australia 14th National Convention, RMAA, Perth, available at: www.sims.monash.edu.au/research/rcrg/ publications/recordscontinuum/smckp2 (accessed 11 January 2006). 
McLeod, J., Childs, S. and Hardiman, R. (2011), "Accelerating positive change in electronic records managment: headline findings from a major research project”, Archives and Manuscripts, The Journal of the Australian Society of Archivists, Vol. 39 No. 2, pp. 65-93.

Oliver, G. (2004), "Investigating information culture: a comparative case study research design and methods", Archival Science, Vol. 4 Nos 3-4, pp. 287-314.

Oliver, G. (2008), "Information culture: exploration of differing values and attitudes to information in organizations", Journal of Documentation, Vol. 64 No. 3, pp. 363-385.

Oliver, G. (2010), "Assessing information culture: a framework for records managers", $i R M A$ Information and Records Management Annual, pp. 31-37.

Oliver, G. (2011), organizational Culture for Information Managers, Chandos Publishing, Oxford.

Patton, Q.M. (2002), Qualitative Research \& Evaluation Methods, Sage Publications, London.

Rubin, H.J.I. and Rubin, S. (2005), Qualitative Interviewing: The Art of Hearing Data, Sage Publications, Thousand Oaks, CA.

Torres, L., Pina, V. and Royo, S. (2005), "E-government and the transformation of public administrations in EU countries: beyond NPM or just a second wave of reforms?", Online Information Review, Vol. 29 No. 5, pp. 531-553.

Widén-Wulff, G. (2000), "Business information culture: a qualitative study of the information culture in the Finnish insurance business", Information Research, Vol. 5 No. 3, available at: http://informationr.net/ir/5-3/paper77.html (accessed 17 January, 2012).

Yin, K.R. (2009), Case Study Research, Design and Methods, 4th ed., Sage Publications, Thousand Oaks, CA.

\section{Appendix}

Interview schedule, Proscovia Svärd,PhD Candidate, (P.Svard@uva.nl), The Institute for History and Culture, Faculty of Humanities, University of Amsterdam

The purpose of this interview schedule is to elicit responses regarding information culture in relation to records management in Sundsvall and Härnösand municipalities. (A third case study might be added if permission to carry out research is granted). The questions are directed at different categories of personnel. Information culture and the way it influences records management is an area that has not been explored. In 2010, Douglas defined information culture as: "an emerging complex system of values, attitudes and behaviours that influence how information is used in an organization. Information culture exists in the context of and is influenced by an organizational culture and the wider environment" (Douglas, 2010, p. 388). The data that will be collected will enable me to answer my research questions and hence contribute to a better understanding of how information culture impacts records management. The interview will be 45 minutes long and on consent of the interviewee, it will be recorded.

According to research on information culture (Oliver, 2011; Douglas, 2010; Choo et al., 2008) attitudes, norms and values impact the way records are handled in an organization. This is what constitutes an information culture espoused by an organization. This research applies Oliver's (2011) framework for assessment of information culture in organizations. The framework constitutes three levels:

- Level 1 is the fundamental layer of an organization's culture and among many it includes, respect for information as evidence, respect for information as knowledge, willingness to share information and trust in information.

- Level 2 addresses employee skills, knowledge and experience related to information management.

- Level 3 is about information governance and trust in organization information systems (see Table AI). 
RMJ

24,1

Level One

\section{0}

Level Two

Level Three

\section{Table AI.}

Levels
Respect for records as evidence. Recognition and awareness of the need to capture, organize, manage and pluralize records for the purposes of accountability

(1) Is the management of records prioritized and integrated in the business processes? If yes, how is this done?

(2) Are there professional staff employed to undertake records management?

(3) What function does the records management staff have in the organization? What type of responsibilities do they have and do you have contact with them and if yes, for what?

(4) Are you actively informed about the way you should handle public records? If so, is it management or the records professionals? Is this something positive or negative to your work?

(5) Do you consider records management to be part of your responsibilities?

(6) Are you aware of the laws governing the records that you receive or produce?

(7) Do you think these laws are necessary? If yes, explain why.

(8) Does the municipality live up to these laws?

(9) What efforts are put into the effective capture, organization and management of records?

(10) Does the municipality have records management systems where records are preserved with metadata?.

Skills, knowledge and experience related to records management

(1) What is your understanding of records management? What does it involve?

(2) Do you receive training in records management?

(3) Is training in records management considered important by management?

(4) How do you perceive your records management skills to be?

(5) How do you think the way you handle records affects they are preserved?

(6) What are the consequences of bad records management?

(7) Are international standards applied to the management of records in the organization?

(8) Does your unit meet to discuss and plan the management of records and is there collaboration among unit members?

Information Governance and Trust In information governance (Oliver, 2010, Davenport, 1997) defines the different information models that can be found in organizations and these include, information federalism, information feudalism, information monarchy, information anarchy and technocratic utopia. Trust is about the employees trust in in-house records management systems.

(1) How does management deal with records management?

(2) Does management expressly demand that you handle public information according to the laws governing it?

(3) Is there a records management policy?

(4) Are there document management schedules?

(5) Are they adhered to?

(6) What challenges does the organization face in maintaining records based on best practice?

(7) How are records management challenges resolved in the organization?

(8) Are there common systems to facilitate the use of each other's records?

(9) Do you reuse records?

(10) Are there any significant barriers to re-use such as insufficient access to information systems?

(11) How do you retrieve records and what retrieval methods do you use?

(12) Do you use the information systems put in place to manage records?

(13) Are records withheld from systems? 


\section{About the author}

Proscovia Svärd is a $\mathrm{PhD}$ candidate at the Faculty of Humanities, University of Amsterdam. She did her licentiate research which resulted in a thesis entitled "The Interface Between Enterprise Content Management and Records Management in Changing organizations", at Mid Sweden University, Sweden. She has worked as an Archivist, Research Administrator for the Program on Post-Conflict Transition, the State and Civil Society and Project-Co-ordinator for a Nordic Documentation Project on the Liberation Struggles in Southern Africa (www.liberationafrica.se) at the Nordic Africa Institute, Uppsala, Sweden. She has a Licentiate Degree in Data and Systems Sciences, BA and MA in Archives and Information Science and a BSc in Media and Information Science. Her research interests are; enterprise content management, records management, long-term preservation of information, Truth and Reconciliation Commissions and their documentation processes, the role of archives in enhancing accountability and transparency in Government institutions, information access and the link to democracy and development. Proscovia Svärd can be contacted at: P.Svard@uva.nl

\section{Impact of information culture}

To purchase reprints of this article please e-mail: reprints@emeraldinsight.com Or visit our web site for further details: www.emeraldinsight.com/reprints 